\title{
Assessing the reproductive health of men with occupational exposures
}

\author{
Steven M Schrader, Katherine L Marlow
}

The earliest report linking environmental (occupational) exposure to adverse human male reproductive effects dates back to1775 when an English physician, Percival Pott, reported a high incidence of scrotal cancer in chimney sweeps. This observation led to safety regulations in the form of bathing requirements for these workers. The fact that male-mediated reproductive harm in humans may be a result of toxicant exposures did not become firmly established until relatively recently, when Lancranjan studied lead-exposed workers in Romania in 1975, and later in 1977, when Whorton examined the effects of dibromochloropropane (DBCP) on male workers in California. Since these discoveries, several additional human reproductive toxicants have been identified through the convergence of laboratory and observational findings. Many research gaps remain, as the pool of potential human exposures with undetermined effects on male reproduction is vast. This review provides an overview of methods used to study the effects of exposures on male reproduction and their reproductive health, with a primary emphasis on the implementation and interpretation of human studies. Emphasis will be on occupational exposures, although much of the information is also useful in assessing environmental studies, occupational exposures are usually much higher and better defined.

Asian Journal of Andrology (2014) 16, (23-30); doi: 10.4103/1008-682X.122352; published online: 16 December 2013

Keywords: accessory glands; endocrine; epidemiology; semen; sexual function; sperm; testis; toxicology

\section{INITIATION OF HUMAN STUDIES}

Most research on human male reproductive health has been stimulated by studies of the effects of exposures in animals and their offspring. Many research gaps remain, as the pool of potential human exposures with undetermined effects on male reproduction is vast. More than 72 million unique organic and inorganic substances are currently registered in the Chemical Abstract Service database of the American Chemical Society, with about 15000 new substances added per day at this writing. ${ }^{1}$ Roughly 84000 chemicals are in commerce in the US ${ }^{2}$ and over 100000 in the European Union (EU), ${ }^{3}$ but male reproductive toxicity has only been thoroughly investigated in a small fraction of them. Under the 2007 European regulation on Registration, Evaluation, Authorization and Restriction of Chemicals (REACH), manufacturers and importers are required to identify and share chemical risks which are then added to a European Union registry for subsequent evaluation and public dissemination. ${ }^{4}$

Surveillance and anecdotal observations also have led to investigations of male reproductive exposures. Studies of dibromochloropropane (DBCP) were initiated after informal discussions of infertility problems among wives attending a softball game. ${ }^{5}$ The petroleum refinery industry exemplifies a profession in which the workers themselves had concerns regarding their reproductive health. ${ }^{6}$ Work-related accidents such as contamination of a truck driver and rescue workers responding to a truck accident related bromine spill ${ }^{7}$ or the nuclear radiation disaster in Chernobyl ${ }^{8}$ also have led to studies. Adverse health effects observed in case studies of high dose accidental exposures may provide clues to potential health effects that should be studied at lower exposures. Industry may also initiate occupational research to validate anecdotal claims. ${ }^{9}$

Relying on anecdotes and surveillance to identify possible male reproductive toxicants, however, is haphazard. In contrast to more overt health hazards, male occupational reproductive hazards can be "silent"; this presents an obstacle to identifying emerging hazards using human populations. To illustrate, suppose hypothetically that an effect such as reversible sterility is, in fact, induced by an unsuspected male reproductive toxicant. Although this is an extremely severe effect, only the subset of nonvasectomized male men trying to achieve pregnancy (or at least having regular sexual intercourse) with reproductive-aged, noncontracepting partners during the exposure period, who underwent a diagnostic work-up during the exposure period, and then were informed they were sterile, would even be aware a problem exists. As another example, a broader group of workers may be privately aware of an overt outcome such as diminished sexual function, but (as with infertility) misattribute it to normal aging, etc., and have a similar reluctance to disclose it. And so, even after a reproductive health problem is acknowledged, it may only be known to a man's partner, and perhaps, his private physician. It is probably safe to assert, therefore, that a cluster of male reproductive health problems is far less apt to "sound the alarm" than a cluster of more commonly diagnosed and socially discussed health problems. Therefore, the toxicologist, the physician, the epidemiologist, the worker himself, the labor union, and the

Centers for Disease Control and Prevention, National Institute for Occupational Safety and Health, Division of Applied Research and Technology, Cincinnati, OH, USA. The findings and conclusions in this report are those of the authors and do not necessarily represent the views of the National Institute for Occupational Safety and Health. Correspondence: Dr. S Schrader (sms4@cdc.gov)

Received: 19-07-2013; Revised: 24-08-2013; Accepted: 28-08-2013 
corporation need to continue to be "on the lookout" for potential exposures and study populations.

\section{STUDIES OF HUMAN POPULATIONS: DESIGNS AND CONSIDERATIONS}

Animal and human experimentation on the male reproductive system have constraints, both ethical and pragmatic. Unlike animal studies, human studies cannot rely on random assignment of subjects to treatment or control groups or controlling all extraneous variables like diet and environment. Consequently, alternative designs and analysis methods for observational studies have been developed with the goal of controlling or minimizing biases introduced by sub- or non-randomization. Population-based studies, broadly, are one such category of designs. The goal of sample selection in a population-based study is to represent the target human population of interest. To the extent sample representativeness is achieved, results of population-based studies may be considered externally valid (i.e., generalizable) for testing associations.

Epidemiological studies of occupational exposures and adverse male reproductive effects may follow several different study epidemiological designs. Involving industrial hygiene measures and biomarkers can better define the exposure and the level of exposure. Few occupational settings have single exposures to potential reproductive toxicants, but a milieu of chemical and physical conditions. Some concurrent exposures can be additive, and in some cases synergistic, amplifying the observed effect. ${ }^{10,11} \mathrm{~A}$ careful assessment of the chemical and environment should be made.

\section{Cohort Studies}

Reproductive cohort studies evaluate the frequency of adverse outcomes among a group defined by common characteristics (e.g., demography, geography, and exposures) by following them over time.

In such a study, baseline data are collected, and individuals are followed longitudinally, either prospectively or retrospectively, for a specific reproductive outcome. The results are then compared by differences in exposure to determine the association with the outcome. In time-to-pregnancy (TTP) studies, for example, cohorts of couples attempting to become pregnant are followed either prospectively or retrospectively until pregnancy is achieved. Men may be informants for prospective TTP studies, particularly when paternal behaviors or exposures are thought to impact the outcome of interest. Similarly, retrospective TTP cohorts may be constructed based on the male partner's exposures. Results of prospective and retrospective TTP studies may differ, as pregnancy attempts are the usual sampling unit for prospective studies; whereas, the pregnancy itself is the usual sampling unit for retrospective studies. ${ }^{12}$ In general, less recall bias is anticipated among prospective than retrospective cohorts, and for retrospective cohort studies, less recall bias among shorter-term than longer-term studies. Examples of prospective cohort studies are men involved in pesticide application due to the seasonal application of pesticides. ${ }^{13,14}$ The period of pesticide use is known and the men can be followed evaluating their reproductive health. If semen analyses are conducted to predict reproductive outcome, correct timing is needed. Since the time for spermatogenesis and delivery of mature sperm to the ejaculate is approximately 72 days, if primary spermatogonia were affected by exposure, this would not be observed in a time frame which covered less than 80-90 days. Thus, a study of "summer hire" workers may not make valid conclusions regarding the effect on spermatogenesis of a 2-month exposure among pesticide applicators, although other reproductive functions can be assessed..$^{13}$ An example of a long-term retrospective cohort study was the 1989 Vietnam experience study, in which military veterans were grouped according to whether or not they had served in Vietnam from 1967 to $1972 .{ }^{15}$ This study was able to detect subsequent differences between the groups in semen quality and TTP, but revealed little about the reproductive health of the individuals at the time of exposure.

\section{Case-control Studies}

Case-control or case-referent studies involve comparing the frequency of toxic exposure of men who have experienced reproductive dysfunction to those without such a medical history. ${ }^{16}$ Case-control studies provide an efficient design to detect the association of rare outcomes with toxic exposures. Infertility clinics can provide a good resource for case-control studies. ${ }^{17}$ A strong advantage of using infertile couples in such studies is the individual and patient follow-up that is not normally done in research studies. The infertility clinic case-control studies tend to emphasize pregnancy success and not the etiology of the infertility ${ }^{18}$ Tielemans et al, ${ }^{19}$ utilized a case-control study of infertility patients to show an association between aromatic solvents and abnormal semen quality. Study subjects were in four groups: normal semen analysis (controls), those with a semen value below the World Health Organization (WHO) reference value, those with very poor semen quality (sperm concentration $<5$ million, percent motile $<10 \%$, or normal morphology $<5 \%$ ), and azoospermic men. The use of a case-crossover design of patients undergoing in vitro fertilization is a powerful design where exposure is needed during follow-up, the exposure must have an immediate effect and the exposure's immediate effect is not carried over to the next cycle.

Nassar and coinvestigators ${ }^{20}$ applied the case-control study method to examine an association between parental exposure to endocrine disrupting chemicals (EDCs) and hypospadias among their offspring. Cases were obtained from a state birth defects registry in Australia and controls were a random sample of non-cases from birth records from the same state. Maternal and paternal occupations, as well as information on other potential confounders and covariates, were obtained from birth records. Maternal and paternal exposure to EDCs was estimated for the various occupations. Use of this approach permitted separate estimates of the odds of hypospadias given maternal and paternal prenatal EDC exposures.

Case-control studies are subject to considerable bias when cases do not arise from the same population as controls. When cases and controls are selected from existing cohorts, such designs are described as "nested" case-control studies; this approach lowers the risk of bias as both cases and controls are drawn from the same population, plus it is cost-effective.

\section{Cross-sectional Studies}

The cross-sectional study design is the most common design for investigating the effects of occupational exposure and adverse male reproductive health. In most occupational field investigations, the workers have been employed for some time and have been exposed to the potential hazard and are usually currently exposed. A cross-sectional study provides a "snapshot" of men's exposures and reproductive outcomes as they exist at a fixed point in time. Traditionally, the study team recruits workers, determines current exposure, work history, as well as current and historic reproductive health. In contrast with cohort and case-control studies, a purely cross-sectional study does not usually include either prospective or retrospective exposure or outcome information. There are, however, cross-sectional studies where outcome prevalence is associated with a past exposure if the time of exposure can be ascertained. Cross-sectional prospective occupational studies can be conducted where the current exposure is noted and reproductive health is studied prospectively as in TTP studies. ${ }^{21}$ Cross-sectional studies are 
often less expensive to implement than other study designs and so are often used to examine hypothesized relationships. Cross-sectional data can be used to estimate the prevalence, not incidence, of an outcome. Cross-sectional studies can show associations between exposure and reproductive health, but they do not show causation. ${ }^{22}$

\section{Clinic-based Studies}

Case studies typically involve a physician in a clinic or hospital reporting reproductive effects in exposed workers. These reports involve the evaluation of individuals, groups of men with the same exposure (e.g., occupation, lifestyle), or clinical treatment following accidental exposure. While such reports rarely provide a definitive relationship between exposure and male reproductive effects, they can serve as sentinel reports that initiate further studies.

Some case studies provide unique information that would not be observed by using other study methods. One such study of a firearms instructor ${ }^{23}$ demonstrates the effect of lead on sperm. The instructor had fathered one son, but became infertile as a result of an elevated blood lead concentration of $88 \mu \mathrm{gdl}^{-1}$. During the next 3 years, the lead exposure was decreased and he was placed on chelation therapy. His sperm count increased as his blood levels decreased, and he subsequently fathered another child after his blood level of lead fell below $30 \mathrm{\mu gdl}^{-1}$. Similarly, after men exposed to high levels of kepone in the work environment were treated with cholestyramine to offset the toxic action of kepone, their sperm count and sperm motility increased accordingly. ${ }^{24}$

\section{Surveillance}

Surveillance of human male reproductive health encompasses monitoring levels of adverse reproductive health effects in male populations and adverse effects on their offspring. Large scale surveillance programs are ideally population-based, and thus describe information useful for tracking rates (e.g., incidence, prevalence) and ratios (e.g., standardized fertility, birth, and sex ratios) over time and comparing rates and ratios within and between populations. These systems are primarily registry based and maintained or supported by government agencies. Use of these systems to track male reproductive outcomes among subgroups of exposed men (e.g., occupational groups, etc.) or to study exposure-reproductive disease relationships, are limited by the extent such systems fail to capture men's exposures. For instance, Fitzgerald et al. ${ }^{25}$ found "father's usual occupation" listed on birth certificates by only one-third of states in the US. Because exposure variables available from surveillance databases are often generalized, careful attention to the appropriate use and interpretation of such data is indicated. Brender et al. ${ }^{26}$ found agreement on paternal occupation between reported (maternal interview) and recorded (birth certificate) data sources $63 \%$ of the time.

Surveillance to monitor male reproductive health among targeted population subgroups (e.g., occupational, clinical) is also conducted. In the US, a surveillance strategy for evaluating men working with known male reproductive toxicants was proposed and conducted by a team from the University of California. ${ }^{27}$ However, this program had many problems and was eventually discontinued. ${ }^{28}$ While this first attempt was discouraging, surveillance remains warranted as chemicals such as lead and ethylene glycol ethers remain in the US workplace, posing a potential hazard to the reproductive health of the male worker. Better surveillance is needed to monitor employees working with these and other occupational toxicants. The addition of biological markers of reproduction and semen characteristics, along with evaluation for use of occupational exposure data from existing sources (e.g., birth certificates) are potential activities to enhance human surveillance. ${ }^{29}$ Surveillance of reproductive health findings across multiple studies may also be conducted in the form of systematic reviews or meta-analyses, such as multinational efforts to monitor for the existence of declines in men's sperm counts. ${ }^{30}$

\section{ASSESSMENTS OF MALE REPRODUCTIVE HEALTH}

Toxicants can attack the male reproductive system at one of several sites, or at multiple sites. These sites and the assays associated with their respective functions are discussed individually. This does not necessarily indicate that there exists an absolute one-to-one relationship between a particular measurement and the associated site of action. These sites include the neuroendocrine system, the testes, accessory sex glands, and sexual function.

The establishment of a male reproductive profile for assessing reproductive potential for both individual and population investigations is essential. The same profile can be used for both types of studies, but there are some basic differences in methodology. The endocrine assessment profile illustrated in Table $\mathbf{1}$ is being used by the National Institute for Occupational Safety and Health (NIOSH) to assess populations exposed to potential reproductive toxicants. Differences between assessing the individual $v s$ the population will be noted. A summary of assessments and specific methodologies follow. If individual data ( $v s$ population comparisons) are to be used, care should be taken to compare the results with the normal range of results of the laboratory conducting the analysis

Table 1: Endocrine profile for assessing reproductive toxicant effects

\begin{tabular}{lccc}
\hline Hormone & \multicolumn{3}{c}{ Fluid for measurement } \\
\cline { 2 - 4 } & Saliva & Blood & Urine \\
\hline Luteinizing & $\mathrm{X}$ & $\mathrm{X}$ \\
Follicle stimulating & $\mathrm{X}$ & $\mathrm{X}$ \\
Inhibin B & & \\
Testosterone & & \\
Total & & $\mathrm{X}$ & $\mathrm{X}$ \\
Free & $\mathrm{X}$ & $\mathrm{X}$ & \\
\hline
\end{tabular}

Table 2: Examples of workplace exposures affecting reproductive health

\begin{tabular}{|c|c|}
\hline Site of action & Examples \\
\hline \multicolumn{2}{|l|}{ Neuroendocrine } \\
\hline Hormone profile & $\begin{array}{l}\text { Insecticide, }{ }^{36} \text { lead, },^{37-39} \text { organophosphate, }{ }^{14,40,41} \text { DDE, }{ }^{42} \\
\text { manganese, }{ }^{43} \text { phthalates }{ }^{44}\end{array}$ \\
\hline \multicolumn{2}{|l|}{ Testicles } \\
\hline $\begin{array}{l}\text { Sperm } \\
\text { concentration }\end{array}$ & $\begin{array}{l}\text { Lead, }{ }^{37,45} \text { diesel exhaust, }{ }^{46} \text { pesticide }{ }^{47} \text { bisphenol } A,{ }^{48} \\
\text { organophosphate, }{ }^{49} \text { chromium, }{ }^{50} \text { paraquat/malathion }{ }^{47}\end{array}$ \\
\hline Sperm morphology & $\begin{array}{l}\text { Insecticides, }{ }^{36} \text { lead, }{ }^{45} \text { carbon disulfide, }{ }^{51} \text { pesticide, }{ }^{47} \\
\text { bisphenol } A,{ }^{48} \text { petrochemical, }{ }^{52} \text { carbofuran, }{ }^{53} \text { nickel }{ }^{50}\end{array}$ \\
\hline Sperm genetics & $\begin{array}{l}\text { Phthalate, }{ }^{54} \text { styrene }^{55} \text {, organophosphate }{ }^{56}, \text { carby }^{57} \text {, } \\
\text { fenvalerate }^{58} \text {, lead }{ }^{45,59} \text {, benzene }{ }^{60}\end{array}$ \\
\hline \multicolumn{2}{|l|}{ Accessory sex glands } \\
\hline Toxicant in semen & Lead, $^{38}$ trichloroethylene, ${ }^{61}$ boron, ${ }^{62,63}$ cadmium $^{64}$ \\
\hline Semen volume & Lead, ${ }^{38}$ organophosphate, ${ }^{65}$ paraquat/malathion ${ }^{47}$ \\
\hline Sperm viability & Carbon disulfide, ${ }^{51}$ bisphenol $A,{ }^{48}$ lead $^{45}$ \\
\hline Sperm motility & $\begin{array}{l}\text { Insecticides, }{ }^{36} \text { diesel exhaust, }{ }^{46} \text { lead, }{ }^{45} \text { carbon disulfide, }{ }^{51} \\
\text { phthalate, }{ }^{54} \text { pesticide, }{ }^{47} \text { bisphenol } A,{ }^{48} \text { fenvalerate, }{ }^{67} \\
\text { petrochemical, }{ }^{52} \text { welding, }{ }^{50} \mathrm{~N}, \mathrm{~N} \text {-dimethylformamide, } \\
\text { abamectin, }{ }^{69} \text { paraquat/malathion }{ }^{47}\end{array}$ \\
\hline \multicolumn{2}{|l|}{ Sexual function } \\
\hline Libido & Carbon disulfide, ${ }^{51}$ bisphenol $A^{70}$ \\
\hline Erectile function & Bisphenol $A,{ }^{70}$ bicycle saddles ${ }^{66}$ \\
\hline Penis sensitivity & Bicycle saddles ${ }^{66}$ \\
\hline Ejaculatory function & Bisphenol $A^{70}$ \\
\hline
\end{tabular}


and not published values. If a population-based study is being conducted, a concurrent comparison cohort must be used and the analyses should be blind to exposure status. The WHO has published reference values for various semen parameters. ${ }^{31}$

Table 2 provides examples of occupational exposures which have been shown to have negative effects on one or more sites of male reproduction. The most effective data collection is achieved by establishing a temporary laboratory near the worksite for blood collection and designed such that the semen samples can be conveniently submitted. Studies with multiple study sites or long recruitment periods may make establishing a temporary laboratory impractical. In this case, blood can be collected by a local nurse or clinic and serum shipped to the analytical lab. The semen sample can be collected, placed in a cold (not frozen) container, and shipped to the andrology lab. ${ }^{71}$ When semen is shipped in this manner, sperm motility and viability measures are compromised; but, the other semen parameters can be assessed. ${ }^{72}$

\section{Neuroendocrine System}

The endocrine and nervous systems work in concert to coordinate the function of the various components of the reproductive axis, drawing upon inputs that are external (e.g., sexual cues, temperature) and internal (e.g., checks and balances between endocrine tissue function, metabolic status). The reproductive neuroendocrine system involves the concert of several endocrine glands including the hypothalamus, the pituitary, and the testes. Reproductive toxicants may affect one or more of these glands or their interaction. The reproductive endocrine status of the male can be assessed by measuring the hormones in the blood, urine, and/or saliva, depending on the hormone. The principal hormones of interest for assessing the effects of reproductive toxicants in men are luteinizing hormone $(\mathrm{LH})$, follicle stimulating hormone (FSH), inhibin B, and testosterone.

Since the circulating profile of $\mathrm{LH}$ is pulsatile, the status of this hormone for the individual, if measured in blood, is best estimated in serial samples. The pooled results of three samples collected at 20-min intervals will provide the best estimate of mean concentration. ${ }^{73}$ Yet, multiple blood draws often result in poor participation rates of workers. If a population is being evaluated, a single blood sample per individual may suffice. ${ }^{74}$ Alternatively, an integral of its pulsatile secretion may be obtained by measuring LH in urine. ${ }^{75}$

Circulating FSH levels are not as variable as those for LH. This is attributable in part to a longer circulating half-life for FSH compared to $\mathrm{LH}^{76}{ }^{7}$ Thus, analysis of a single blood sample for an individual will provide a more reliable estimate of FSH than for LH. FSH can also be measured in urine for the sake of convenience. Neither gonadotropin is exuded into the saliva.

While the circhoral variation of inhibin B levels secreted by the Sertoli cells into the serum is also nominal, there exists a significant diurnal pattern, with higher levels in the early morning hours. ${ }^{77}$ Therefore, inhibin B levels can be assessed with a single serum sample, but efforts should be made to standardize the time of sample collection. Inhibin B cannot be measured meaningfully in urine or saliva.

Approximately $2 \%$ of circulating testosterone is free, with the remainder bound to sex hormone binding globulin (SHBG), albumin, and other serum proteins. The free circulating testosterone is the active component and therefore provides a more accurate marker of physiologically available testosterone than does total circulating testosterone under conditions when SHBG concentration or binding may be variable. ${ }^{73}$ Circulating testosterone levels, like those for LH, exhibit circhoral fluctuations. Estimates of free and total testosterone can be determined in single blood samples, but may be improved by assaying multiple blood samples and pooling the results.

Serum levels of total and free testosterone can be measured directly. However, serum free testosterone concentrations are more accurately determined by calculating them from serum concentrations of total testosterone, SHBG, albumin, and an association constant. ${ }^{78}$ Alternatively, a single measurement in urine of testosterone after sample hydrolysis or of a testosterone metabolite (e.g., androsterone, etiocholanolone, or testosterone glucuronide) provides a convenient index of total testosterone. ${ }^{79}$ Quantifying testosterone in saliva affords a convenient alternative to blood sampling, while providing a measure of the unbound, biologically active component of circulating testosterone. ${ }^{80}$ If measuring steroid hormone metabolites in urine, consideration should be given to the potential that the exposure being studied may alter the metabolism of excreted metabolites. This is especially pertinent since most metabolites are formed by the liver, a target of many toxicants. Lead, for example, reduces the amount of sulfated steroids that were excreted into the urine. ${ }^{81}$ Precision of urinary measurements is improved by normalizing urinary flow rate (concentration) by adjusting for urinary levels of creatinine or osmolality.

Recently, the utility of assessing SHBG in clinical medicine has been noted ${ }^{82}$ and there are reports of associations of endocrine active toxicants with the level of SHBG. ${ }^{83,84}$ Therefore, the level of SHBG may become a useful biomarker in the assessment male reproductive health.

Circulating levels for the reproductive hormones become elevated during the night as the male enters puberty. In men, secretion of testosterone and inhibin B maintain this diurnal pattern through adulthood, with peak values in early morning and declining towards late afternoon. ${ }^{77}$ This pattern appears to be driven by sleep, not a circadian rhythm. ${ }^{85}$ Thus, samples for assessing testosterone and inhibin B should be collected at approximately the same time of day to avoid variations due to diurnal secretory patterns.

In summary, Table 1 lists the primary hormones for assessing reproductive toxicity effects in men. $\mathrm{FSH}, \mathrm{LH}$, inhibin $\mathrm{B}$, and testosterone can all be evaluated in a population-based study by assessing the hormone levels in a single blood sample from each man, preferable at about the same time of day. A wide variety of potentially toxic occupational exposures have been reported to alter levels of one or more of these hormones (Table 2).

\section{Testes}

Semen analysis provides a useful profile of the function of the male reproductive system. The $\mathrm{WHO}^{31}$ has published reference ranges for semen parameters. Specific instructions should be provided to each man to ensure that the semen sample is properly collected by masturbation after a set time of abstinence (usually 2-3 days) and delivered to the laboratory within 1 hour from the time of ejaculation. The men should be instructed to maintain the semen at room temperature, avoiding any temperature shock to the sperm cells. At the time of collecting the semen sample, each subject should record the duration of abstinence, time of semen collection, and any information regarding sample collection loss or spillage. Providing a label on the jar facilitates the recording of this information.

Semen analyses can be conducted in two phases. The initial evaluation of the sample should be conducted when the sample arrives at the laboratory (or field site) and should consist of recording the temperature, turbidity, color, liquefaction time, and volume of the semen. Temperature shock to the semen sample can affect many sperm parameters. An inexpensive temperature logging monitor (Maxim Integrated, San Jose, 
CA, USA) on the collection jar is useful to determine the temperatures to which the semen has been exposed since collection. Motility assessments, viability estimates, sperm counts, the preparation of slides, and preservation of seminal plasma should also be conducted at this time. Sperm motility should be assessed objectively either with computer-assisted sperm analysis (CASA), or by another objective assessment. ${ }^{86}$ Motility assessment can be conducted onsite with the fresh ejaculate or video recorded for future analyses. Morphologic and morphometric analyses of sperm on slides may be conducted at a later time.

Sperm viability may be determined by vital $\operatorname{stain}^{87}$ or by hypo-osmotic swelling (HOS assay). ${ }^{88}$ The HOS assay determines the structural and functional integrity of the cell membrane. ${ }^{89}$

Sperm morphology should be estimated on fixed, stained semen smears. During the past 30 years, several schemes have been presented for the assessment of normal and abnormal sperm morphologies. Since 1980, WHO has adopted different sperm morphology classifications several times. Currently, there are two widely accepted classification systems, WHO $3^{\text {rd }}$ Edition $^{90}$ (often called traditional morphology) and WHO $5^{\text {th }}$ Edition (often called strict morphology). ${ }^{31}$ The main difference between these classification systems is how they classify a "borderline normal" sperm. They are reported as normal with traditional scheme and abnormal with the strict scheme. ${ }^{91}$ Morphometric computer analysis systems provide objective assessments of individual sperm head size and shape. Sperm morphometry is routinely used as part of the assessment of reproductive hazards to male workers. ${ }^{92}$

Sperm concentration, sperm morphology, and sperm head morphometry all provide indices of the integrity of spermatogenesis and spermiogenesis.

Epidemiological studies of large populations have demonstrated increased frequency of adverse pregnancies in women whose husbands were working in various occupations. ${ }^{20,93-95}$ Case-control studies also can associate a specific adverse outcome with paternal exposure. ${ }^{96}$ Such studies are very important in hypothesis generating for genetic damage to sperm, however, genetic damage is difficult to detect in human sperm. ${ }^{97}$ This is primarily because the chromosomes are in interphase, that is, with no replication and no production of proteins. Some methods being used to detect genetic damage with varying success are fluorescent in situ hybridization (FISH) ${ }^{98-100}$ of certain chromosomes, terminal transferase dUTP nick end labeling (TUNEL), comet, and the sperm chromatin stability assay. ${ }^{101-104}$ DNA adducts may also provide information about spermatogenesis. Several reports have shown that paternal exposure may affect pregnancy or the health of the offspring. These data have stimulated research into the genetic stability of the sperm cell and the cause/effect relationships of damage to sperm.

\section{Accessory Sex Glands}

Seminal plasma is not essential for fertilization; thus, the artificial insemination of sperm collected from the epididymis results in conception. On the other hand, seminal plasma contributes importantly to the normal coitus-fertilization scenario. Seminal plasma serves as a vehicle for sperm transport, a buffer from the hostile acidic vaginal environment, and an initial energy source for the sperm. Cervical mucus prevents passage of seminal plasma into the uterus. Some constituents of seminal plasma, however, are carried into the uterus to the site of fertilization by adhering to the sperm membrane.

The viability and motility of spermatozoa in seminal plasma are typically a reflection of seminal plasma quality. Alterations in sperm viability or alterations in sperm motility parameters would suggest an effect on the accessory sex glands.
Biochemical analysis of seminal plasma provides insights into the function of the accessory sex glands. Chemicals that are secreted primarily by each of the glands of this system are typically selected to serve as a marker for each respective gland. Measuring volume provides additional general information on the nature of seminal plasma.

Seminal plasma may be analyzed for the presence of a toxicant or its metabolite. Heavy metals have been detected in seminal plasma using atomic absorption spectrophotometry, ${ }^{105}$ while halogenated hydrocarbons have been measured in seminal fluid by gas chromatography after extraction ${ }^{105}$ or protein-limiting filtration. ${ }^{106}$ A toxicant or its metabolite may act directly on accessory sex glands to alter the quality or quantity of their secretions. Alternatively, the toxicant may enter the seminal plasma ${ }^{107-109}$ and thereby affect the sperm and the body of the female partner after intercourse, or may be carried to the site of fertilization on the sperm membrane and affect the ova or conceptus. Reports of occupational effects on the accessory sex glands in humans are referenced in Table 2.

Several sperm assessment methods measure the sperm function ${ }^{110}$ and may evaluate sperm across more than one of the subjective toxicant site divisions outlined above. The penetration of sperm through cervical mucus (or viscous fluids stimulating cervical mucus), ${ }^{111-113}$ the penetration of sperm into a zona-free hamster egg (sperm penetration assay, SPA), ${ }^{114}$ the penetration of sperm through a zona pellucida removed from immature human ova (hemizona assay), and the binding to hyaluronic acid ${ }^{115}$ have been shown to evaluate different sperm functions. ${ }^{116,117}$ These have not been widely utilized in assessing reproductive toxicants in the occupational setting.

\section{Sexual Function}

Human sexual function refers to the integrated activities of the testes and secondary sex glands, the endocrine control systems, and the central nervous system-based behavioral and psychological components of reproduction (libido). Erection, ejaculation, and orgasm are three distinct, independent physiological and psychodynamic events that normally occur concurrently in men. If details regarding functions or mechanisms are desired see Kandeel et al. ${ }^{118}$

Burnett ${ }^{119}$ published a review on the effects of environmental exposures on erectile function. Assessment of occupational exposure-induced anomalies of sexual function is difficult. The researcher usually must rely on the testimony and recall of the worker regarding his sexual function. This testimony may often be confounded by the bias of the individual to guard his ego or masculine image, or to attribute a preexisting libido problem to exposures at work.

Burris and colleague ${ }^{120}$ reported application of a monitor (Rigiscan $\left.{ }^{\circ}\right)$ for assessing erection at home. The assessment of erectile function using the Rigiscan has been used successfully in the occupational setting in studies of bicycle patrol officers. ${ }^{66,121}$

The assessment of ejaculate volume may provide information on the integrity of the emission phase of ejaculation. This is complicated by effects on the accessory sex glands. Thus, a semen sample of reduced volume but with a normal ratio of constituents (marker chemicals), supports a diagnosis of an emission phase defect.

The numbness or loss of feeling of the penis can be objectively measured using a biothesiometer. The equipment can easily be set up in a private room (i.e., a lavatory) and the computer operator can be in an adjoining room. The study subject places his penis in a plastic trough and the computer operator sends signals to the apparatus to increase or decrease vibration to detect the level of vibration that can be sensed by the penis. ${ }^{66}$ 


\section{FUTURE ASSESSMENT METHODS}

There are several new methods that may play a key role in future studies of toxicant exposures and male reproduction, ${ }^{32-34}$ especially epigenetic disorders. ${ }^{35}$ As new methods are added to the reproductive health profile there are some potential limitations that need to be considered; are methods practical in an environmental or occupational field setting (or easily preserved for later assessment); is there adequate statistical power with typical field study sample sizes assessing accuracy and precision; and is there enough semen available in most specimens to analyze all of the measures requiring a prioritization scheme.

\section{QUESTIONS FROM THE PANEL}

Q1: In the planning of future studies, is it important to take ethnicity of the study population into consideration? Please discuss this.

A1: There are several studies comparing reproductive assessments in isolated ethnic populations. These include the Inuit and aboriginal populations. In most occupational studies the populations being studied or compared are generally racially and ethnically mixed. Although there may appear to be ethnic differences, they may actually be geographic or regional differences. This has been noted in the United States, ${ }^{122,123}$ Europe, ${ }^{124}$ France, ${ }^{125}$ China, ${ }^{126,127}$ and Japan. ${ }^{128}$ These regional differences may include ethnic differences, but also social economic status, lifestyle, climate, and other regional exposures such as pesticides, air pollution, etc. There may also be some ethnic differences within communities and regions due to discrimination and ethnic opportunities. ${ }^{129}$ All these potential confounders need be considered when planning occupational field studies.

Q2: Cocktail effects due to lifestyle, for example, smoking.

A2: Lifestyle and previous exposures can have a major effect on reproductive health. There is a relatively new approach to assessing the comprehensive assessment of an individual's lifetime exposure history from preconception, through sensitive windows, to current and concurrent exposures called the exposome. ${ }^{71,130}$ While these technologies are being developed, the most useful approach is to ensure that control and exposed populations remain very similar. The information gathered on each individual should include current lifestyle information (e.g., illness, smoking or use of alcohol, medication, pesticide, etc.) determining whether one population of workers is more or less likely to have the lifestyle effect (i.e., if toxic exposure is explosive, workers may be less likely to be smokers $)^{131}$ and most importantly modeling your statistical analyses correcting for covariates or in extreme cases removing individuals from the analyses.

\section{COMPETING INTERESTS}

The authors declare that there are no competing interests.

\section{REFERENCES}

1 American Chemical Society, CAS Abstract Service Division. Chemical Abstract Service (CAS) registry and CAS registry numbers, 2013. Available from: http:// www.cas.org/content/chemical-substances/faqs [Last accessed on $2013 \mathrm{Jul}$ 17].

2 US EPA. Available from: http://www.epa.gov/opptintr/existingchemicals/pubs/ tscainventory/basic.html. [Last accessed on 2013 Jul 17].

3 Environmental Directorate General, European Commission. REACH in brief, 2007. Available from: http://ec.europa.eu/environment/chemicals/reach/pdf/2007_02_ reach_in_brief.pdf [Last accessed on 2013 Jul 17].

4 European Commission. Available from: http://ec.europa.eu/environment/chemicals/ reach/reach_intro.htm. [Last accessed on 2013 Jul 17].

5 Whorton D, Foliart D. DBCP: eleven years later. Symposium on the assessment of reproductive hazards in the workplace. Presented Cincinnati, OH, June 16, 1988. Reprod Tox1988; 2: 155-61.

6 Rosenberg MJ, Wyrobek AJ, Ratcliffe J, Gordon LA, Watchmaker G, et al. Sperm as an indicator of reproductive risk among petroleum refinery workers. $\mathrm{Br} J$ Ind Med 1985; 42: 123-7.
7 Potashnik G, Carel R, Belmaker I, Levine M. Spermatogenesis and reproductive performance following human accidental exposure to bromine vapor. Reprod Toxicol 1992; 6: 171-4.

8 Birioukov A, Meurer M, Peter RU, Braun-Falco O, Plewig G. Male reproductive system in patients exposed to ionizing irradiation in the Chernobyl accident. Arch Androl 1993; 30: 99-104.

9 Hamill PV, Steinberger E, Levine RJ, RodriguezRigau LJ, Lemeshow S, et al. The epidemiologic assessment of male reproductive hazard from occupational exposure to TDA and DNT. J Occup Med 1982; 24: 985-93.

10 SCHER, SCCS, SCENIHR, Opinion on the toxicity and assessment of Chemical Mixtures. 2012. p. 13-16. Available from: http://ec.europa.eu/health/scientific_committees/ environmental_risks/docs/scher_o_155.pdf [Last accessed on 2013 Aug 15].

11 HESIS. Understanding toxic substances: an introduction to chemical hazards in the workplace. 2008. p. 9. Available from: http://www.cdph.ca.gov/programs/hesis/ Documents/introtoxsubstances.pdf [Last accessed on 2013 Aug 15].

12 Rothman KJ, Greenland S, Lash LT. In: Seigafuse S, Bierig L, editors. Modern Epidemiology. $3^{\text {rd }}$ ed., Ch. 31, 33. Philadelphia: Lippincott Williams and Wilkins; 2008.

13 Schrader SM, Turner TW, Ratcliffe JM. The effects of ethylene dibromide on semen quality: a comparison of short term and chronic exposure. Reprod Toxicol 1988; 2: 191-8.

14 Aguilar-Garduño C, Lacasaña M, Blanco-Muñoz J, Rodriguez-Barranco M, Hernández $A F$, et al. Changes in male hormone profile after occupational organophosphate exposure. A longitudinal study. J Toxicol 2013; 307: 55-65.

15 DeStefano F, Annest JL, Kresnow MJ, Schrader SM, Katz DF. Semen characteristics of Vietnam veterans. Reprod Toxicol 1989; 3: 165-73.

16 Levin SM. Problems and pitfalls in conducting epidemiological research in the area of reproductive toxicology. Am J Ind Med 1983; 4: 349-64.

17 Rachootin P, Olsen J. The risk of infertility and delayed conception associated with exposures in the Danish workplace. J Occup Med 1983; 25: 394-402.

18 Olsen J, Bonde JP, Hjøllund NH, Basso O, Ernst E. Using infertile patients in epidemiologic studies on subfecundity and embryonal loss. Hum Reprod Update 2005; 11: 607-11

19 Tielemans E, Burdorf A, te Velde ER, Weber RF, van Kooij RJ, et al. Occupationally related exposures and reduced semen quality: a case-control study. Fertil Steril 1999; 71: 690-6.

20 Nassar N, Abeywardana P, Barker A, Bower C. Parental occupational exposure to potential endocrine disrupting chemicals and risk of hypospadias in infants. Occup Environ Med 2010; 67: 585-9.

21 Snijder CA, Brouwers MM, Jaddoe VW, Hofman A, Roeleveld N, et al. Occupational exposure to endocrine disruptors and time to pregnancy among couples in a large birth cohort study: the Generation R Study. Fertil Steril 2011; 95: 2067-72.

22 EFSA Panel on food contact materials, enzymes, flavorings and processing aids (CEF). Scientific Opinion on Bishpenol A: evaluation of a study investigating its neurodevelopmental toxicity, review of recent scientific literature on its toxicity and advice on the Danish risk assessment of Bisphenol A. EFSA J 2010; 8:9:1829. [116 pp.].

23 Fisher-Fischbein J, Fischbein A, Melnick HD, Bardin CW. Correlation between biochemical indicators of lead exposure and semen quality in a lead-poisoned firearms instructor. JAMA 1987; 257: 803-5.

24 Guzelian PS. Therapeutic approaches for chlordecone poisoning in humans. J Toxicol Environ Health 1981; 8: 757-66.

25 Fitzgerald E, Wartenberg D, Thompson WD, Houston A. Birth and fetal death records and environmental exposures: promising data elements for environmental public health tracking of reproductive outcomes. Public Health Rep 2009; 124:825-30.

26 Brender JD, Suarez L, Langlois PH. Validity of parental work information on the birth certificate. BMC Public Health 2008; 8: 95

27 Schenker MB, Samuels SJ, Perkins C, Lewis EL, Katz DF, et al. Prospective surveillance of semen quality in the workplace. J Occup Med 1988; 30: 336-44.

28 Samuels SJ. Lessons from a surveillance program of semen quality. Reprod Toxicol 1988; 2: 229-31.

29 Lawson CC, Schnorr TM, Daston GP, Grajewski B, Marcus M, et al. An occupational reproductive research agenda for the third millennium. Environ Health Perspect 2003; 111: 584-92.

30 Swan SH, Elkin EP, Fenster L. The question of declining sperm density revisited: an analysis of 101 studies published 1934-1996. Environ Health Perspect 2000; 108: 961-6.

31 World Health Organization. WHO laboratory manual for the examination and processing of human semen, $5^{\text {th }}$ ed. Geneva, Switzerland: WHO World Press; 2010

32 Natali A, Turek PJ. An assessment of new sperm tests for male infertility. Urology 2011; 77: 1027-34.

33 Baker MA. The "omics revolution and our understanding of sperm cell biology. Asian J Androl 2011; 13: 6-10.

34 De Jonge C. Semen analysis: looking for an upgrade in class. Fertil Steril 2012; 97: 260-6.

35 Boissonnas CC, Jouannet $\mathrm{P}$, James $\mathrm{H}$. Epigenetic disorders and male subfertility. Fertil Steril 2013; 99: 624-31.

36 Kamijima M, Hibi H, Gotoh M, Taki K, Saito I, et al. A survey of semen indices in insecticide sprayers. J Occup Health 2004; 46: 109-18. 
37 Mahmoud A, Kiss P, Vanhoorne M, De Bacquer D, Comhaire F. Is inhibin B involved in the toxic effect of lead on male reproduction? Int J Androl 2005; 28:3: 150-5.

38 Alexander BH, Checkoway H, Faustman EM, van Netten C, Muller $\mathrm{CH}$, et al. Contrasting associations of blood and semen lead concentrations with semen quality among lead smelter workers. Am J Ind Med 1998; 34: 464-9.

39 Hsieh SJ, Chiu YW, Li WF, Wu CH, Chen HI, et al. Increased concentrations of serum inhibin $\mathrm{B}$ among male workers with long-term moderate lead exposure. $\mathrm{Sc}$ Total Environ 2009; 407: 2603-7.

40 Yucra S, Rubio J, Gasco M, Gonzales C, Steenland K, et al. Semen quality and reproductive levels in Peruvian pesticide sprayers. Int J Occup Environ Health 2006; 12: 355-61.

41 Pérez-Herrera N, Polanco-Minaya H, Salazar-Arredondo E, Solís-Heredia MJ, Hernández-Ochoa I, et al. PON1Q192R genetic polymorphism modifies organophosphorous pesticide effects on semen quality and DNA integrity in agricultural workers from southern Mexico. Toxicol Appl Pharmacol 2008; 230 : 261-8.

42 Blanco-Muñoz J, Lacasaña M, Aguilar-Garduño C, Rodríguez-Barranco N, Bassol S, et al. Effect of exposure to p, p'-DDE on male hormone profile in Mexican flower growers. Occup Environ Med 2012; 69: 5-11.

43 Ellingsen DG, Chashchin V, Haug E, Chashchin M, Tkachenko V, et al. An epidemiological study of reproductive function biomarkers in male welders. Biomarkers 2007; 12: 497-509.

44 Pan G, Hanaoka T, Yu L, Na J, Yamano Y, et al. Associations between hazard indices of di-n-butylphthalate and di-2-ethylhexylphthalate exposure and serum reproductive hormone levels among occupationally exposed and unexposed Chinese men. Int J Androl 2011; 34: e397-406.

45 Naha N, Chowdhury AR. Inorganic lead exposure in battery and paint factory: effect on human sperm structure and functional activity. J UOEH 2006; 28:2: 157-71.

46 Guven A, Kayikci A, Cam K, Arbak P, Balbay O, et al. Alterations in semen parameters of toll collectors working at motorways: does diesel exposure induce detrimental effects on semen? Andrologia 2008; 40: 346-51.

47 Hossain F, Ali O, D'Souza UJ, Naing DK. Effects of pesticide use on semen quality among farmers in rural areas of Sabah, Malaysia. J Occup Health 2010; 52:353-60.

48 Li DK, Zhou Z, Miao M, He Y, Wang J, et al. Urine bisphenol-A level in relation to semen quality. Fertil Steril 2011; 95: 625-30.

49 Recio-Vega R, Ocampo-Gómez G, Borja-Aburto VH, Moran-Martínez J Cebrian-Garcia ME. Organophosphorus pesticide exposure decreases sperm quality: association between sperm parameters and urinary pesticide levels. J Appl Toxicol 2008; 28: 674-80.

50 Danadevi K, Rozati R, Reddy PP, Grover P. Semen quality of Indian welders occupationally exposed to nickel and chromium. Reprod Toxicol 2003; 17: 451-6.

51 Ma JY, Ji JJ, Qing D, Liu WD, Wang SQ, et al. The effects of carbon disulfide on male sexual function and semen quality. Toxicol Ind Health 2010; 26:6: 375-82.

52 Kim TH, Myung SC, Hong YP, Yang YJ, Kim SY, et al. Light and transmission electron microscopic comparisons of sperms between petrochemical factory workers and public servants in a nonindustrialized area. Fertil Steril 2010; 94: 2864-7.

53 Gallegos-Avila G, Ancer-Rodríguez J, Niderhauser-García A, Ortega-Martínez M, Jaramillo-Rangel G. Multinucleation of spermatozoa and spermatids in infertile men chronically exposed to carbofuran. Reprod Toxicol 2010; 29: 458-60.

54 Huang LP, Lee CC, Hsu PC, Shih TS. The association between semen quality in workers and the concentration of di (2-ethylhexyl) phthalate in polyvinyl chloride pellet plant air. Fertil Steril 2011; 96: 90-4.

55 Migliore L, Naccarati A, Zanello A, Scarpato R, Bramanti L, et al. Assessment of sperm DNA integrity in workers exposed to styrene. Hum Reprod 2002; 17 : 2912-18.

56 Sánchez-Peña LC, Reyes BE, López-Carrillo L, Recio R, Morán-Martínez J, et al. Organophosphorous pesticide exposure alters sperm chromatin structure in Mexican agricultural workers. Toxicol Appl Pharmacol 2004; 196: 108-13.

57 Xia Y, Cheng S, Bian Q, Xu L, Collins MD, et al. Genotoxic effects on spermatozoa of carbaryl-exposed workers. Toxicol Sci 2005; 85: 615-23.

58 Bian Q, Xu LC, Wang SL, Xia YK, Tan LF, et al. Study on the relation between occupational fenvalerate exposure and spermatozoa DNA damage of pesticide factory workers. Occup Environ Med 2004; 61: 999-1005.

59 Hsu PC, Chang HY, Guo YL, Liu YC, Shih TS. Effect of smoking on blood lead levels in workers and role of reactive oxygen species in lead-induced sperm chromatin DNA damage. Fertil Steril 2009; 91: 1096-103.

60 Marchetti F, Eskenazi B, Weldon RH, Li G, Zhang LL, et al. Occupational exposure to benzene and chromosomal structural aberrations in the sperm of Chinese men. Environ Health Perspect 2012; 120: 229-34.

61 Forkert PG, Lash L, Tardif R, Tanphaichitr N, Vandevoort C, et al. Identification of trichloroethylene and its metabolites in human seminal fluid of workers exposed to trichloroethylene. Drug Metab Dispos 2003; 31: 306-11.

62 Duydu Y, Başaran N, Üstündağ A, Aydin S, Ündeğer U, et al. Reproductive toxicity parameters and biological monitoring in occupationally and environmentally boron-exposed persons in Bandirma, Turkey. Arch Toxicol 2011; 85: 589-600.

63 Xing X, Wu G, Wei F, Liu P, Wei H, et al. Biomarkers of environmental and workplace boron exposure. J Occup Environ Hyg 2008; 5: 141-7.

64 Akinloye O, Arowojolu AO, Shittu OB, Anetor JI. Cadmium toxicity: a possible cause of male infertility in Nigeria. Reprod Biol 2006: 6: 17-30.
65 Yucra S, Gasco M, Rubio J, Gonzales GF. Semen quality in Peruvian pesticide applicators: association between urinary organophosphate metabolites and semen parameters. Environ Health 2008; 7: 59.

66 Schrader SM, Breitenstein MJ, Lowe BD. Cutting off the nose to save the penis. J Sex Med 2008; 5: 1932-40.

67 Lifeng T, Shoulin W, Junmin J, Xuezhao S, Yannan L, et al. Effects of fenvalerate exposure on semen quality among occupational workers. Contraception 2006; 73: 92-6.

68 Chang HY, Shih TS, Guo YL, Tsai CY, Hsu PC. Sperm function in workers exposed to N, N-dimethylformamide in the synthetic leather industry. Fertil Steril 2004; 81: 1589-94.

69 Celik-Ozenci C, Tasatargil A, Tekcan M, Sati L, Gungor E, et al. Effect of abamectin exposure on semen parameters indicative of reduced sperm maturity: a study on farmworkers in Antalya (Turkey). Andrologia 2012; 44: 388-95.

70 Li DK, Zhou Z, Miao M, He Y, Qing D, et al. Relationship between urine bisphenol-A level and declining male sexual function. J Androl 2010; 31: 500-6.

71 Buck Louis GM, Schisterman EF, Sweeney AM, Wilcosky TC, Gore-Langton RE, et al. Designing prospective cohort studies for assessing reproductive and developmental toxicity during sensitive windows of human reproduction and development - The LIFE Study. Paediatr Perinat Epidemiol 2011; 25: 413-24.

72 Turner TW, Schrader SM. Sperm migration assay as measure of recently ejaculated sperm motility in specimens shipped overnight. J Androl 2006; 27 Suppl:58.

73 Sokol RZ. Endocrine evaluation in the assessment of male reproductive hazards. Reprod Toxicol 1988; 2: 217-22.

74 Schrader SM, Turner TW, Breitenstein MJ, Simon SD. Measuring male reproductive hormones for occupational field studies. J Occup Med 1993; 35: 574-6.

75 Kulin HE, Bell PM, Santen RJ, Ferber AJ. Integration of pulsatile gonadotropin secretion by timed urinary measurements: an accurate and sensitive 3-hour test. J Clin Endocrinol Metab 1975; 40: 783-9.

76 Smith KD, Tcholakian RK, Chowdhury M, Steinberger E. Rapid oscillations in plasma levels of testosterone, luteinizing hormone, and follicle-stimulating hormone in men. Fertil Steril 1974; 25: 965-75.

77 Carlsen E, Olsson C, Petersen JH, Andersson AM, Skakkebaek NE. Diurnal rhythm in serum levels of inhibin $B$ in normal men: relation to testicular steroids and gonadotropins. J Clin Endocrinol Metab 1999; 84: 1664-9.

78 Vermeulen A, Verdonck L, Kaufman JM. A critical evaluation of simple methods for the estimation of free testosterone in serum. J Clin Endocrinol Metab 1999; 84: 3666-72.

79 Bardin CW. Pituitary-testicular axis, reproductive endocrinology. In: Yen SSC Jaffe RB. editors. Philadelphia: WB Saunders; 1986. p. 177-99.

80 Riad-Fahmy D, Read GF, Walker RF, Griffiths K. Steroids in saliva for assessing endocrine function. Endocr Rev 1982; 3: 367-95.

81 Apostoli P, Romeo L, Peroni E, Ferioli A, Ferrari S, et al. Steroid hormone sulphation in lead workers. Br J Ind Med 1989; 46: 204-8.

82 Hammond GL, Wu TS, Simard M. Evolving utility of sex hormone-binding globulin measurements in clinical medicine. Curr Opin Endocrinol Diabetes Obes 2012; 19: 183-9.

83 Meeker JD, Johnson PI, Camann D, Hauser R. Polybrominated diphenyl ether concentrations in house dust are related to hormone levels in men. Sci Total Environ 2009; 407: 3425-9.

84 Jurewicz J, Hanke W. Exposure to phthalates: reproductive outcome and children health. A review of epidemiological studies. Int J Occup Med Environ Health 2011; 24: $115-41$

85 Axelsson J, Ingre M, Akerstedt T, Holmbäck U. Effects of acutely displaced sleep on testosterone. J Clin Endocrinol Metab 2005; 90: 4530-5.

86 Keel A. The semen analysis. In: Keel BA, Webster BW, editors. CRC Handbook of the Laboratory Diagnosis and Treatment of Infertility. Boca Raton, Florida: CRC Press, 1990. p. 27-69.

87 Eliasson R, Treichl L. Supravital staining of human spermatozoa. Fertil Steril 1971; 22: $134-7$

88 Jeyendran RS, Van der Ven HH, Perez-Palaez M, Crabo BG, Zaneveld LJ. Development of an assay to assess the functional integrity of the human sperm membrane and its relationship to other semen characteristics. J Reprod Fertil 1984; 70: 219-28.

89 Schrader SM, Platek SF, Zaneveld LJ, Perez-Palaez M, Jeyendran RS. Sperm viability: a comparison of analytical methods. Andrologia 1986; 18: 530-8.

90 World Health Organization. WHO laboratory manual for the examination of human semen and sperm-cervical mucus interaction. $3^{\text {rd }}$ ed. Cambridge: Cambridge University Press; 1992

91 Rothmann SA, Bort AM, Quigley J, Pillow R. Sperm morphology classification: a rational method for schemes adopted by the World Health Organization. In Carrell KT, Aston KI, editors. Spermiogenesis and Spermatogenesis: methods and Protocols, Methods in Molecular Biology. New York: Humana Press; 2013. p. 27-37.

92 Schrader SM, Ratcliffe JM, Turner TW, Hornung RW. The use of new field methods of semen analysis in the study of occupational hazards to reproduction: the example of ethylene dibromide. J Occup Med 1987; 29: 963-6.

93 Schrader SM, Kanitz MH. Occupational hazards to male reproduction, in State of the art reviews in occupational medicine: reproductive hazards. In: Gold E, Schenker M, Lasley B, editors. Philadelphia: Hanley and Belfus, Inc.; 1994. p. 405-14. 
94 dos Santos Silva I, Pizzi C, Evans A, Evans S, De Stavola B. Reproductive history and adverse pregnancy outcomes in commercial flight crew and air trafffic control officers in the United Kingdom. J Occup Environ Med 2009; 51: 1298-305.

95 Baste V, Moen BE, Oftedal G, Strand LÅ, Bjørge L, et al. Pregnancy outcomes after paternal radiofrequency field exposure aboard fast patrol boats. J Occup Environ Med 2012; 54: 431-8.

96 Aguilar-Garduño C, Lacasaña M, Blanco-Muñoz J, Borja-Aburto VH, García AM. Parental occupational exposure to organic solvents and anencephaly in Mexico. Occup Environ Med 2010; 67: 32-7.

97 Delbès G, Hales BF, Robaire B. Toxicants and human sperm chromatin. Mol Hum Reprod 2010; 16: 14-22.

98 Holmes JM, Martin RH. Aneuploidy detection in human sperm nuclei using fluorescence in situ hybridization. Hum Genet 1993; 91: 20-4.

99 Wyrobek AJ, Robbins WA, Mehraein Y, Pinkel D, Weier HU. Detection of sex chromosomal aneuploidies $X-X, Y-Y$, and $X-Y$ in human sperm using two-chromosome fluorescence in situ hybridization. Am J Med Genet 1994; 53: 1-7.

100 Bischoff FZ, Nguyen DD, Burt KJ, Shaffer LG. Estimates of aneuploidy using multicolor fluorescence in situ hybridization on human sperm. Cytogenet Cell Genet 1994; 66: 237-43.

101 Evenson DP. Flow cytometry of acridine orange-stained sperm is a rapid and practical method for monitoring occupational exposure to genotoxicants, in Monitoring Occupational Genotoxicity. In: Sorsa M, Norppa H, editors. New York: Alan R. Liss; 1986. p. 121-32.

102 Evenson DP, Jost LK, Baer RK, Turner TW, Schrader SM. Individuality of DNA denaturation patterns in human sperm as measured by the sperm chromatin structure assay. Reprod Toxicol 1991; 5: 115-25.

103 Spano M, Evenson DP. Flow cytometric studies in reproductive toxicology, in New horizons in biological dosimetry. Gledhill BL, Mauro F, editors. New York: Wiley-Liss; 1991. p. 497-511.

104 Evenson DP, Wixon R. Environmental toxicants cause sperm DNA fragmentation as detected by sperm chromatin structure assay (SCSA). Toxicol Appl Pharmacol 2005; 207 Suppl 2: 532-7.

105 Stachel B, Dougherty RC, Lahl U, Schlösser M, Zeschmar B. Toxic environmental chemicals in human semen: analytical method and case studies. Andrologia 1989; 21: 282-91.

106 Zikarge A. Cross-sectional study of ethylene dibromide-induced alterations of seminal plasma biochemistry as a function of post-testicular toxicity with relationships to some indices of semen analysis and endocrine profile. Dissertation to the University of Texas Health Science Center, Houston, TX, 1986.

107 Mann T, Lutwak-Mann C. Passage of chemicals into human and animal semen: mechanisms and significance. Crit Rev Toxicol 1982; 11: 1-14.

108 Kumar S, Mishra VV. Review: toxicants in reproductive fluid and in vitro fertilization (IVF) outcome. Toxicol Ind Health 2010; 26: 505-11.

109 Arbuckle TE, Schrader SM, Cole D, Hall JC, Bancej CM, et al. 2,4-Dichlorophenoxyacetic acid residues in semen of Ontario farmers. Reprod Toxicol 1999; 13: 421-9.

110 Aitken RJ. Development of in vitro tests of human sperm function: a diagnostic tool and model system for toxicological analyses. Toxicol In Vitro 1990; 4: 560-9.

111 Katz DF, Overstreet JW, Hanson FW. A new quantitative test for sperm penetration into cervical mucus. Fertil Steril 1980; 33: 179-86.

112 Niederberger CS, Lamb DJ, Glinz M, Lipshultz LI, Scully NF. Tests of sperm function for evaluation of the male: penetrak and Tru-Trax. Fertil Steril 1993; 60: 319-23.

113 Biljan MM, Taylor CT, Manasse PR, Joughin EC, Kingsland CR, et al. Evaluation of different sperm function tests as screening methods for male fertilization potential--the value of the sperm migration test. Fertil Steril 1994; 62: 591-8.
114 Rogers BJ. Use of the SPA in assessing toxic effects on male fertilizing potential. Reprod Toxicol 1988; 2: 233-40.

115 Prinosilova P, Kruger T, Sati L, Ozkavukcu S, Vigue L, et al. Selectivity of hyaluronic acid binding for spermatozoa with normal Tygerberg strict morphology. Reprod Biomed Online 2009; 18: 177-83.

116 Coddington CC, Franken DR, Burkman LJ, Oosthuizen WT, Kruger T, et al. Functional aspects of human sperm binding to the zona pellucida using the hemizona assay. J Androl 1991; 12: 1-8.

117 Franken DR, Acosta AA, Kruger TF, Lombard CJ, Oehninger S, et al. The hemizona assay: its role in identifying male factor infertility in assisted reproduction. Fertil Steril 1993; 59: 1075-80.

118 Kandeel FR, Koussa VK, Swerdloff RS. Male sexual function and its disorders: physiology, pathophysiology, clinical investigation, and treatment. Endocr Rev 2001; 22: 342-88.

119 Burnett AL. Environmental erectile dysfunction: can the environment really be hazardous to your erectile health? J Androl 2008; 29: 229-36.

120 Burris AS, Banks SM, Sherins RJ. Quantitative assessment of nocturnal penile tumescence and rigidity in normal men using a home monitor. J Androl 1989; 10: 492-7.

121 Schrader SM, Breitenstein MJ, Clark JC, Lowe BD, Turner TW. Nocturnal penile tumescence and rigidity testing of bicycling patrol officers. J Androl 2002; 23: 927-34.

122 Fisch H, Goluboff ET, Olson JH, Feldshuh J, Broder SJ, et al. Semen analyses in 1,283 men from the United States over a 25-year period: no decline in quality. Fertil Steril 1996; 65: 1009-14.

123 Swan SH, Brazil C, Drobnis EZ, Liu F, Kruse RL, et al. Geopraphic differences in semen quality of fertile U.S. males. Environ Health Perspect 2003; 111: 414-20.

124 Jørgensen N, Andersen AG, Eustache F, Irvine DS, Suominen J, et al. Regiona differences in semen quality in Europe. Hum Reprod 2001; 16: 1012-9.

125 Auger J, Jouannet P. Evidence for regional differences of semen quality among fertile French men. Fédération Française des Centres d'Etude et de Conservation des Oeufs et du Sperme humains. Hum Reprod 1997; 12: 740-5.

126 Gao J, Gao ES, Yang Q, Walker M, Wu JQ, et al. Semen quality in a residential, geographic and age representative sample of healthy Chinese men. Hum Reprod 2007; 22: 477-84.

127 Zou Z, Hu H, Song M, Shen Y, Guo X, et al. Semen quality analysis of military personnel from six geographical areas of the People's Republic of China. Fertil Steril 2011; 95: 2018-23.

128 Iwamoto T, Nozawa S, Mieno MN, Yamakawa K, Baba K, et al. Semen quality of 1559 young men from four cities in Japan: a cross-sectional population-based study. BMJ Open 2013; 3: e002222.

129 Dula A, Kurtz S, Samper ML. Occupational and environmental reproductive hazards education and resources for communities of color. Environ Health Perspect 1993; 101 Suppl: 181-9.

130 Buck Louis GM, Yeung E, Sundaram R, Laughon SK, Zhang C. The exposome - exciting opportunities for discoveries in reproductive and perinatal epidemiology. Paediat Perinat Epidemiol 2013; 27: 229-36.

131 Schrader SM, Langford RE, Turner TW, Breitenstein MJ, Clark JC, et al. Reproductive function in relation to duty assignments among military personnel. Reprod Toxicol 1998; 12 : 465-8.

How to cite this article: Schrader SM, Marlow KL. Assessing the reproductive health of men with occupational exposures. Asian $J$ Androl 2013 Dec 16. doi: 10.4103/1008-682X.122352. [Epub ahead of print] 